\title{
Discussion on Laboratory Computer Management and Maintenance of Computer Course
}

\author{
Dan Shao and Juan Wang* \\ College of Cyberspace Security Chengdu University of information technology Chengdu, Sichuan, 610225 \\ *Corresponding author. Email: wangjuan@cuit.edu.cn
}

\begin{abstract}
Computer course pay attention to practical operation ability, and computer class hours in laboratory occupy a large proportion. The assessment of many subjects also depends on the computer test. How to manage the laboratory equipment and network configuration and maintenance has become an important part of the construction of the laboratory room. This paper puts forward some effective methods and specific measures from three aspects of software resource management, hardware resource maintenance and network management and maintenance.
\end{abstract}

Keywords: Computer course, Software resource management, Hardware resource maintenance, Network management.

\section{FOREWORD}

With the popularization of information technology, there is a growing demand for computers in the teaching process of colleges and universities. In particular, computer courses, especially need to cooperate with computer operation practice, strengthen students' handson ability and improve their understanding. Higher requirements are put forward for the management and configuration of laboratory equipment and the construction and maintenance of environment [1]. There are many kinds of laboratory equipment. The management and configuration work not only affects the smooth operation of the computer room, but also directly affects the teaching process of teachers. Therefore, a perfect laboratory management scheme can not only improve the efficiency of students, assist teachers to complete the course explanation, but also prolong the life of equipment, reduce the workload of later maintenance, and make the computer course practice and examination smoothly and orderly.

The daily management and maintenance of the laboratory [2] includes many contents, complicated affairs, involving a wide range of work and heavy workload. Generally speaking, the installation and configuration, maintenance and troubleshooting of all kinds of hardware equipment in the laboratory, the construction and maintenance of various network platforms, the installation and update of software, the guarantee of network security and data security, as well as the security of electricity use, all belong to the scope of laboratory management. Laboratory management can be classified as shown in Figure 1. This paper will discuss the laboratory management measures from three important aspects: software resource management, hardware resource maintenance and network management.

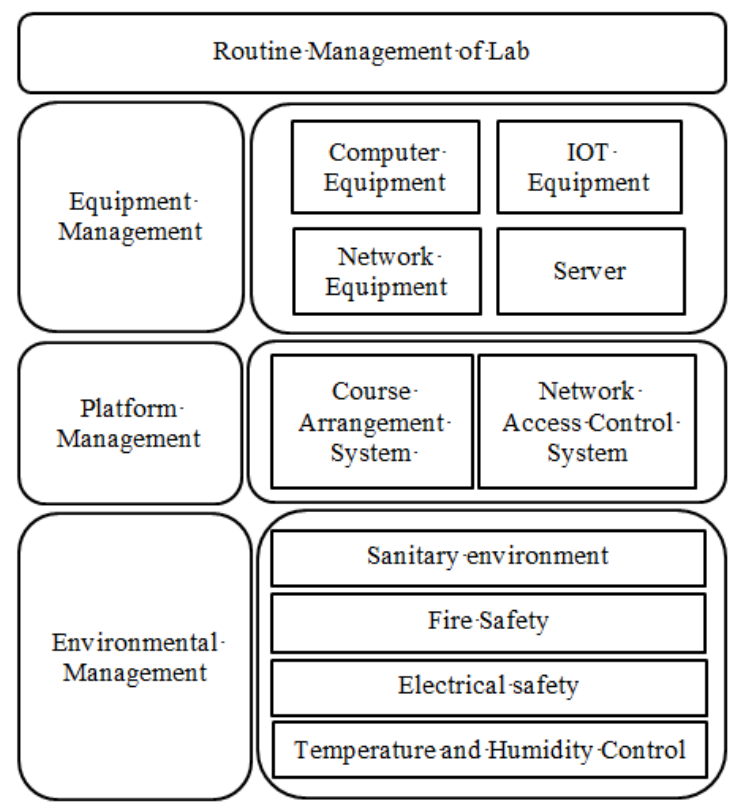

Figure 1 Routine management of the Lab 


\section{HARDWARE RESOURCE MANAGEMENT OF LABORATORY}

\subsection{Network Hardware Equipment}

Laboratory network deployment is the basis for the smooth implementation of computer courses, which requires higher network equipment configuration. The most commonly used network devices [3] are routers and switches. The choice of router in technical specifications and technical specifications needs to meet the daily computer requirements, and needs to choose brand name products such as Cisco series or Ruijie series. The laboratory can configure layer- 3 switch as much as possible according to the demand, so as to solve the problem that the subnet must rely on the router for management after the network segment is divided in the laboratory LAN. Routers and switches and other network equipment have higher requirements on the laboratory operating environment, including ensuring that the temperature of the computer room is within a reasonable range, and cleaning up the dust in time. In addition, you can also view the device $\log$, CPU utilization and other parameters to observe the operation status of the equipment, as a reference for the daily maintenance of network equipment.

\subsection{Computer Hardware Equipment}

In the laboratory equipment, the number of computers is the largest and the types are the most. The reasonable allocation of computer resources can improve the efficiency of the equipment, balance the relationship between the price and the performance of the equipment, and make the best use of all devices to the greatest extent.

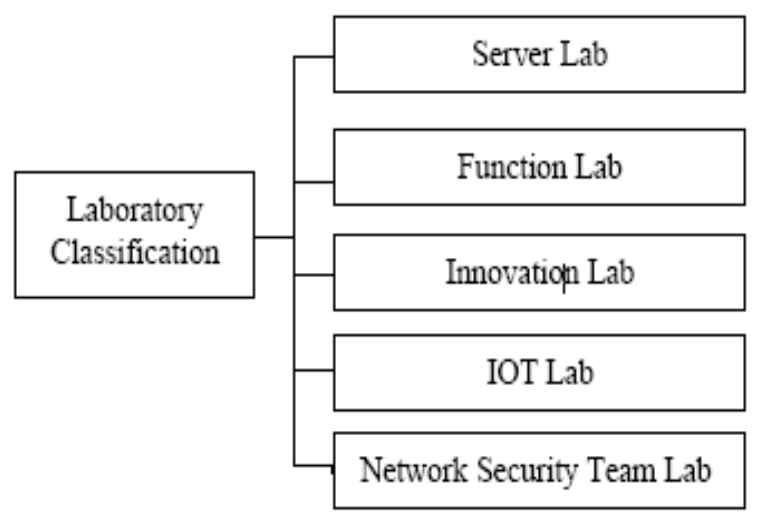

Figure 2 Laboratory Classification

For example, some computer operation courses need to install Oracle and other large software. Computers with higher CPU configuration can be used. Machine learning courses need higher running speed. Computers equipped with high-performance graphics cards can be used. The computer can be classified and placed according to different configurations, and different computer rooms can be arranged according to different needs in students' actual operation. The classification of the computer room is shown in Figure 2.

\subsection{IOT Equipment}

Internet of Things (IOT) courses need to use mobile devices such as Raspberry Pi, RFID experiment box or wireless network card. These devices are updated quickly, and there are many module parts, which belong to the category of consumables. In the experiment process, due to improper plugging and other reasons, it is easy to cause the loss or damage of the equipment. The damage of a certain part of a class of equipment will lead to the whole IOT module unable to be used. Therefore, the maintenance of IOT equipment needs to be more meticulous and frequent. On the one hand, laboratory managers need to timely purchase new version of equipment and damaged and lost parts, do a good job in the borrowing and return registration of Internet of things equipment, and check the number of equipment regularly. On the other hand, teachers need to regulate students' behavior in the process of computer operation, use the equipment reasonably in the experimental course, and take back the equipment in time after class.

\section{SOFTWARE RESOURCE MANAGEMENT OF LABORATORY}

\subsection{System Protection}

The computer operation in the laboratory will change the computer system software and hard disk data inevitably. If the computer is in the initial configuration state before each class, it is necessary to install the restore software or install the hard disk restore card to protect the operating system. The restoration software is easy to install, easy to use, but it also easy to crack and highly dependent on the operating system and hard disk.

Hard disk restore card is a kind of hardware equipment which needs to be installed on the computer. Although the installation process is troublesome, it is more secure and difficult to crack. The manufacturer can be required to provide a restore card when purchasing computer equipment. The process is to set data protection for the current state of the hard disk by using the restore card after installing the operating system and various software. Every time the computer course students do the operation, after the restart, will be restored to the original, and when the next computer class comes, the system software environment is still one the initial state. 


\subsection{Software Maintenance}

With the rapid development of computer technology, the software used in the experiment of computer courses is also updated frequently. In order to facilitate the unified software maintenance of a large number of equipment, two methods can be used to update or replace the relevant software of all equipment in the laboratory.

The first is to use ghost technology. The specific process is to select a hard disk as a template, install all the required software, and use ghost's disk to disk option to copy the contents of this hard disk to all other hard disks in turn. Obviously, this method is not only inefficient, but also needs to dismantle the equipment, which is more troublesome.

The other way is to use the restore card's network simultaneous interpreting function [4]. The specific operation process is to prepare a template computer, install all the software needed on the template machine, and make the relevant configuration. After the preparation is completed, the machine is used as the transmitter, and other machines as the receiving end, which can transmit data, transmit data in a single way, transmit data in single partition, and CMOS data transmission, etc. In this way, the application software can be installed on all student computers in batch, which greatly shortens the working time of installing or updating software and improves the efficiency. However, this method requires that the computer has a restore card installed.

\section{LABORATORY NETWORK MANAGEMENT}

\subsection{Network Access Control}

The network of laboratory computer room mainly involves the category of LAN. The establishment, connection and maintenance of network are the premise and foundation of students' computer operation. Generally speaking, there are two kinds of network requirements for students. One is to access the Internet (external network) during normal computer practice; the other is to only access the school's internal network (such as teaching platform, process assessment system, etc.) in the examination, and can not access the Internet, so as to avoid students searching for answers online. The access control function of AC (access control) device can be used to manage students' Internet behaviour and improve the utilization rate of network and class efficiency. AC is a device that controls the communication between the user and the system. AC access control includes access control, web filtering and timing control.
Winbox is a software based on windows for remote management of ROS, which provides an intuitive and convenient graphical interface. Winbox controls the behavior of surfing the Internet according to the specific IP address segment or each IP address to realize the network segment control of teachers' and students' computers and compete the separation of internal and external networks. The Winbox login interface is shown in Figure 3.

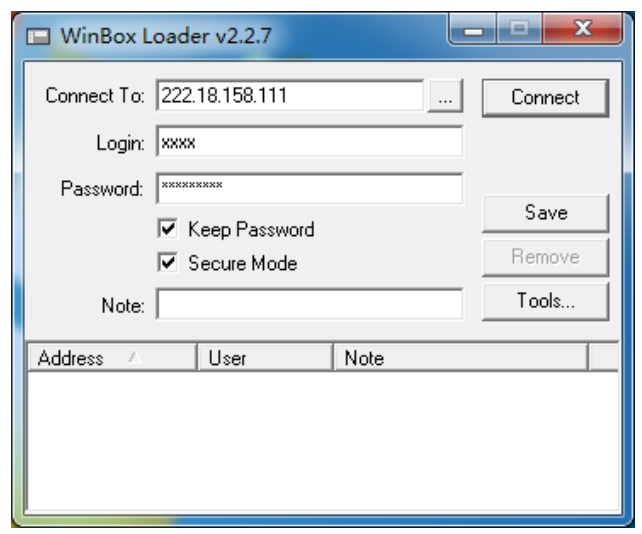

Figure 3 Winbox Login s interface

When the laboratory classification is completed, network access control can be carried out for each class of computer room or a specific computer room. The specific setting is to select the firewall option under the IP tab in Winbox to set the IP address access rights of the computer. Figure 4 shows the network segment configuration established by a laboratory.

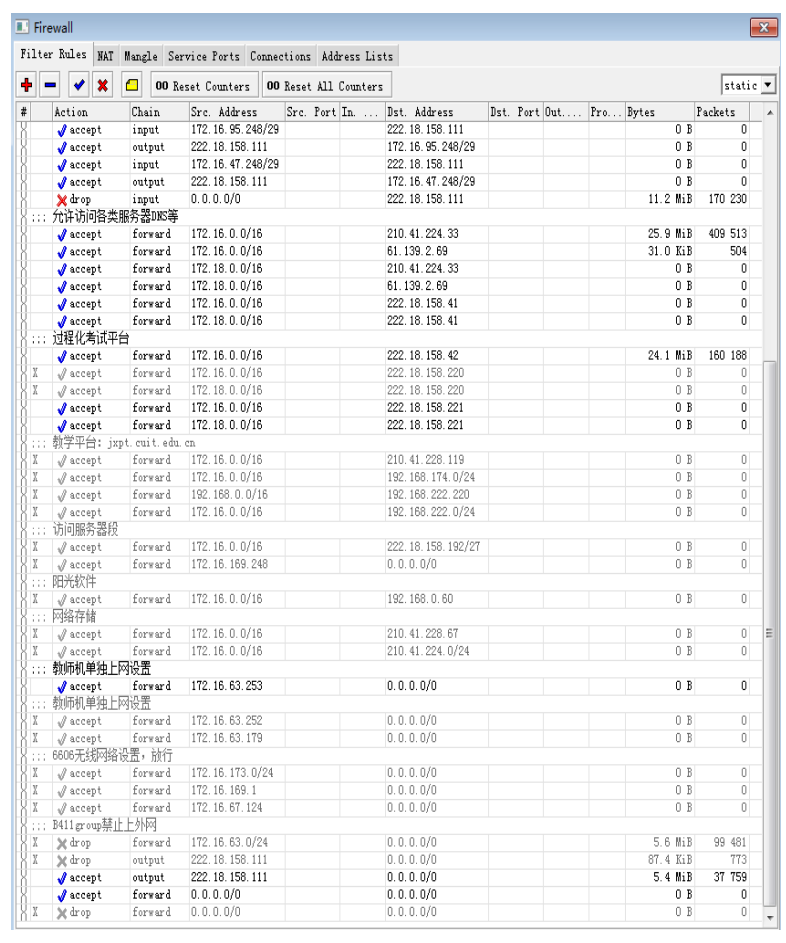

Figure 4 Network segment configurations 
Some access control policies and their functions are shown in Table 1.

Table 1. Access control policies and their functions

\begin{tabular}{|c|c|}
\hline $\begin{array}{c}\text { Access Control } \\
\text { Policy }\end{array}$ & Function \\
\hline $\begin{array}{c}\text { Process assessment } \\
\text { platform }\end{array}$ & $\begin{array}{c}\text { Student examination platform. By } \\
\text { controlling the computer network } \\
\text { segment, students can only visit } \\
\text { the designated laboratory location } \\
\text { and time, so as to prevent students } \\
\text { from cheating. }\end{array}$ \\
\hline $\begin{array}{c}\text { Independent } \\
\text { Tnternet access for } \\
\text { teachers }\end{array}$ & $\begin{array}{c}\text { Students can submit homework or } \\
\text { submit homework in a specific } \\
\text { period of time. }\end{array}$ \\
\hline $\begin{array}{c}\text { When the student network is } \\
\text { disconnected, the teacher } \\
\text { computer network access rights } \\
\text { can be set separately. }\end{array}$ \\
\hline $\begin{array}{c}\text { The Lab is } \\
\text { forbidden to access } \\
\text { the Internet }\end{array}$ & $\begin{array}{c}\text { After this configuration is opened, } \\
\text { it can control the student machine } \\
\text { from accessing the external } \\
\text { network, but it does not affect the } \\
\text { access to the process assessment } \\
\text { platform or teaching platform and } \\
\text { other intranet websites. It is often } \\
\text { used in computer test. }\end{array}$ \\
\hline
\end{tabular}

\subsection{Network Security and Backup}

Laboratory as a public computer room, if not do a good job in security management and control, the computer is easy to be infected with viruses. The computers and other devices are easy to be attacked by viruses because of students visiting malicious websites in the process of computer operation, so that the computers in the whole laboratory are infected by viruses. Therefore, virus prevention is an important part of laboratory safety management [5].

The following methods can be used to maintain laboratory safety. First, install anti-virus software, update and upgrade the virus database in time, enable the system firewall and set a higher level of prevention, make full use of the firewall technology to control the flow of information, filter the data with potential security risks to reduce the risk; secondly, install operating system patches in time to block all possible virus entries; finally, install the hardware device restore card. In case of virus invasion, the system can be restored to its original state by system restart. In addition, it is necessary to manage the laboratory network data and resources, including the configuration of read-write permissions, delete permissions and so on. The authority is assigned according to the level of laboratory management personnel.

If the external environment (such as sudden power failure, fire, etc.), human factors (such as improper operation) or aging of storage equipment may lead to hard disk data damage or other data loss of laboratory server data, data backup should be done in time to prevent the recovery of original data in case of accidents. The corresponding backup work should also be done for the configuration files of network equipment such as switch router, so that the network can be quickly restored by importing the configuration file in case of network failure.

\section{CONCLUSION}

The laboratory has become a necessary teaching environment for computer courses. The use of computer room is more and more frequent, and the demand tends to be more diversified. Laboratory management requires high requirements and heavy tasks. Reasonable measures should be taken to maintain the laboratory equipment, manage the relevant platform of the laboratory and ensure the laboratory environment, so as to maximize the sharing of computer software resources and hardware resources, improve the utilization rate of equipment and improve the computer efficiency [6]. In order to adapt to the renewal of the course and the change of the form, the methods of laboratory computer management should be improved constantly.

\section{ACKNOWLEDGMENTS}

The work is supported by teaching reform project of Chengdu University of Information Technology No. JY2018141, No. BKJX2019030, No. BKJX2019030.

\section{REFERENCES}

[1] Zhu Fuli. Safety management of college training room [J].The Guide of Science \& Education, 2011, 9:5-6.

DOI:

https://doi.org/10.16400/j.cnki.kjdkz.2011.09.118

[2] Zhu Jun. Practice and exploration of management mode of computer room in Colleges and Universities [J]. PR Magazine, 2020, 11: 263-264. DOI: https://doi.org/10.16645/j.cnki.cn115281/c.2020.11.129

[3] Shen Yang. Management and maintenance of LAN in university computer room[J].Technology and Market, 2020, 11: 144-145.

[4] Chen Xiong. Management and maintenance of computer training room in Higher Vocational Colleges under the new situation[J].Electronic Component and Information Technology,2020,4(06):175-176. https://doi.org/10.19772/j.cnki.20964455.2020.6.084

[5] Li Weishi. Management and maintenance of computer room based on LAN [J].Popular Standardization, 2020, 19: 229-230. 
[6] $\mathrm{Hu}$ Guizhi. Discussion on maintenance and management of computer room in Higher Vocational Colleges [J].Computer Knowledge and Technology, 2015, 24: 151-152. https://doi.org/ 10.14004/j.cnki.ckt.2015.2594 